un tipo de estilo barroco, un estilo anti-ciceroniano, yo añadiría) en Inquisiciones, así como la tendencia a re-escribir sus textos basados en las versiones ya publicadas.

La labor que a través de los años ha realizado Daniel Barderston para promover y mejorar la calidad de la crítica borgeana es inmensa y rivaliza con la que Emir Rodríguez Monegal logró en su época. Como señala el crítico mismo, ante la imposibilidad, por varias razones, de poseer repositorios digitales de la obra de Borges en la Internet, es importante procurar que estos textos y las herramientas para entenderlos lleguen a las manos de los investigadores. How Borges Wrote es un libro que se convertirá en un recurso indispensable para los que trabajan con este tema.

José Eduardo González

University of Nebraska-Lincoln

\title{
Lina del Castillo. Crafting a Republic for the World. Scientific, Geographic, and
}

Historiographic Inventions of Colombia. Lincoln: University of Nebraska Press, 2018. 382 pp. ISBN 978-1-4962-0-5483.

"There are no colonial legacies in Spanish America" (No hay legados coloniales en Hispanoamérica, p. 1). Con esta afirmación Lina del Castillo abre su trabajo sobre el proyecto republicano que las élites criollas neogranadinas -tanto liberales como conservadoras- buscaron consolidar a lo largo del siglo XIX a través de un cuerpo de prácticas y conocimientos científicos, tales como la cartografía, la geografía, la estadística, la escritura histórica, la etnografía política y el constitucionalismo. En ese proyecto, la invención de los "legados coloniales" resultaba efectiva para generar la separación de España en términos políticos, económicos, científicos y sociales, pues el proyecto republicano no se asociaría con el pasado colonial -incluso si, como ocurrió, varias de las estructuras de su organización fuesen conservadas o, de cierta manera, replicadas.

Desde una mirada metacrítica, el trabajo sigue esa invención en un amplio corpus primario que incluye prensa, mapas, documentos legales, novelas, entre otros, abordada de la mano de varias aproximaciones metodológicas de la historia social, la geografía, los estudios literarios y la historia constitucional, que la autora señala y desarrolla en los seis capítulos que conforman el libro. Esto, con el fin de mostrar la forma en que prácticas como la geografía y la cartografía y proyectos como la comisión corográfica o el costumbrismo participaron en la producción de territorios, gentes y formas de 
organización sociopolítica y, especialmente, en el desarrollo de un modelo de república basado en la circulación, la creación de mercados internos, la repartición equitativa de la tierra, la educación pública y la moralidad. Los mapas, por ejemplo, más que representar, crearían los territorios en términos de una circulación fluida entre sí y con el centro, ratificando a Bogotá como capital y consolidándola frente a aquellos críticos que podrían disputar su centralidad y frente a las ciudades que rivalizaban con ella, como Quito o Valencia; pero también ubicarían los recursos, organizarían el espacio en términos de una economía modernizada y de un territorio unificado que garantizaría el control de las regiones y podría neutralizar la amenaza de invasiones extranjeras.

Uno de los primeros legados coloniales que aborda Del Castillo es la construcción de España como un poder opuesto al conocimiento y a la ciencia, a través de la edición y difusión de los trabajos de Francisco José de Caldas en un circuito de publicaciones compuesto por el Semanario del Nuevo Reino de Granada, del que Caldas fue editor, el Diario político de Santafé de Bogotá y la Gaceta de Colombia. Así, no solo se invisibilizó la financiación española a las investigaciones encabezadas por una comunidad científica a la que pertenecía el "sabio", sino que también se borró su lealtad inicial a la corona en la instalación de la junta de Santafé en 1810 (36). La fabricación de una narrativa hagiográfica de Caldas, como el sabio único y padre de la ciencia geográfica neogranadina, fue notable en la construcción de este legado; sus trabajos fueron usados para apoyar el orden político-territorial centralista de los republicanos y su fusilamiento fue interpretado no solo como un martirio, sino como el intento de destrucción de un conocimiento que prometía la libertad y el progreso de la república.

La ignorancia emerge como consecuencia de este legado colonial, que habría de ser combatida fervientemente por la república desde publicaciones como las arriba mencionadas, instituciones como el Colegio Militar y el Instituto Caldas, textos como la Peregrinación de Alpha (1853) o Manuela (1858), y proyectos como la Comisión Corográfica, el constitucionalismo o el establecimiento de la educación pública.

Crafting a Republic for the World aborda con suficiencia un espectro temporal amplio que atraviesa todo el siglo XIX; si bien los capítulos pueden seguir un orden temporal, su organización obedece más al abordaje de problemáticas que cruzan las distintas dimensiones del proyecto republicano con prácticas y conocimientos que se desarrollaron y afinaron para su ejecución y administración. En ese sentido, como señala la autora, las élites políticas neogranadinas no sentían que los suyos fuesen conocimientos periféricos; al contrario, se consideraban como creadores de la modernidad, el republicanismo y una activa esfera pública que podrían ser usados en otros lugares.

Dentro de los varios aportes de este trabajo se cuenta la problematización de cierta comprensión de la historia del siglo XIX colombiano como la del antagonismo bipartidista, un enfrentamiento entre liberales y conservadores sin espacios comunes; Del Castillo demuestra que, al menos en el nivel de las élites, se trató en muchos

$1] 1 \frac{\text { Revista Iberoamericana, Vol. LXXXV, Núm. 268, Julio-Septiembre 2019, }}{1075-1115}$ 
aspectos de consensos, como la formulación del proyecto republicano y la construcción de legitimidad desde prácticas científicas en cuanto afirmación de lo local e invención de lo nacional, si bien con intereses en ocasiones manifiestamente contrapuestos. Un caso es la desamortización de bienes de la iglesia, tratada en el sexto capítulo: fueron los liberales en cabeza del presidente Tomás Cipriano de Mosquera quienes adelantaron la desamortización, algo que los conservadores no desaprobaron porque estaban de acuerdo en que representaba un beneficio económico para la república destinado a financiar el sistema de educación pública; lo que sí desaprobaron fue la decisión liberal de entregar la instrucción de los profesores que adelantarían el proyecto de educación pública a maestros protestantes de origen alemán. El consenso sobre la desamortización no se rompió, pero el desacuerdo en la manera de llevar a cabo el proyecto educativo los regresó al poder apoyados por la iglesia católica, a la que no le devolvieron sus bienes, pero sí le entregaron la educación.

Otro ejemplo es la misma invención de los legados coloniales. Mientras para los liberales uno de los principales legados era el "oscurantismo religioso" de la iglesia católica, que los conservadores defendían, para los conservadores había una dimensión neocolonial en el rechazo liberal a muchas cosas de España y en su seguimiento de Francia como modelo político. Al mostrar la funcionalidad de un imaginario colonial en la formulación de los proyectos políticos de ambos partidos, no solamente se hace visible el consenso en la necesidad de tomar una posición frente a la colonia sino también desde esta lectura es posible afirmar que, de cierta manera, la colonia es una invención del siglo XIX. Este sentido permite vincular el trabajo de Lina del Castillo con planteamientos como el de Jacques Heers en La invención de la edad media (Le moyen âge, une imposture, 1992), que aborda lo medieval como un concepto creado en el renacimiento, para descalificarlo, suspender su significación y ocultar su complejidad en la falsa asunción de unidad de los mil años que comprime: el tiempo medio y oscuro entre dos épocas brillantes. Si bien el foco de Crafting a Republic no es la colonia sino, justamente, la construcción de la república, no deja de resonar acá la identificación que los liberales hicieron de la colonia como "nuestra edad media".

En esos trasvases entre edad media, colonia y modernidad yacen aún preguntas sobre los trazados teleológicos de la comprensión histórica. Lejos de separarse de ella, este trabajo nos muestra que la república -y su modernidad-necesitó vivamente de la colonia para construirse a sí misma y que en la hondura de sus más propias creaciones habitan dimensiones coloniales que siguen afectando nuestro mundo de hoy.

María Piedad Quevedo Alvarado Pontificia Universidad Javeriana 